\title{
Obstructive Sleep Apnea During Pregnancy - Myth or Functional Condition with Potentially Serious Complications
}

\author{
Alexander Raynov, MD, PhD', Tanya Andreeva, MD² \\ 1Assistant Professor, Department of Otorhinolaryngology, University Hospital „Lozenetz“, Sofia \\ 2Risk Pregnancy Department, Second Municipal Hospital for Obstetrics and Gynecology „Sheynovo“ PLS, Sofia
}

\begin{abstract}
Sleep disordered breathing (SDB) during pregnancy covers a diverse spectrum of pathological conditions provoked by physiological changes in maternal organism and growing fetus. Most of the symptoms (sleepiness, fatigue, vomiting, snoring, obstructed nasal breathing, etc.) are considered to be „,normally“-related to the physiological changes during pregnancy. In fact, that subtle complains could be a harbinger of more complex disorders, which could remain
\end{abstract}

neglected and undiagnosed by the consulting obstetric and gynecology specialist or primary physician. In view of the potential serious complications related to the SDB during pregnancy it is essential to consider even the mild complains of the pregnant woman as prospective alarming symptoms. Interdisciplinary consultation with otorhinolaryngologist and subsequent detailed polysomnographic study are essential for proper diagnosis in order to avoid possible life threatening complications.

\section{Introduction}

There is a lot of "confusing" specialized terminology associated with sleep disordered breathing applicable in the daily routine clinical practice of the otorhinolaryngologists ${ }^{1}$. According to the second international classification of sleep disorders (ICSD II), based on the strict clinical observations and prŭcised diagnostic criteria, SDB is considered to be a descriptive term for wide range of clinical pathology - simple (habitual) snoring, upper respiratory resistance syndrome (URRS), obstructive sleep apnea (OSA), central sleep apnea (CSA) and obesity-related hypoventilation syndrome $(\mathrm{OHS})^{2}$. Apnea is described as a complete restriction or $\geq 90 \%$ obstruction of the airflow for minimum period of 10 seconds, which is usually associated with reduction of blood oxygen concentration (desaturation) and sleep fragmentation with abrupt change of brain activity from deep sleep to wakefulness (arousals). Hypopnea is presumably less severe condition than apnea and is caused by partial obstruction of the airway. Hypopnea is controversially defined as a different flow limitation during sleep ( $\geq 30 \%$ or $\geq 40 \%$ ) which last at least 10 seconds and are associated with varying desaturation rate $(\geq 4 \%$ or $\geq 3 \%$ respectively). $\underline{\mathrm{AHI}}$ is the average number of apnea and hypopnea episodes for a period of 1 hour during sleep. Respiratory effort-related arousals (RERA) - arousals observed when increased respiratory efforts are generated during sleep for more than 10 seconds as an outcome of elevated resistance of the upper respiratory tract (URT). Cessation of breathing last shorter, don't meet the criteria for hypopnea and apnea, results in transition from the deeper to more superficial sleep stage and disappear subsequently. Usually RERA are ironically called "wannabe hypopnea" and are measured by nasal cannula with pressure transducer, pneumotachograph or esophageal manometry during polysomnography $(\mathrm{PSG})^{3}$. Reparatory distress index (RDI) stands for the sum up of all pathologically registered breathing disturbances - RERA, apnea and hypopnea 
for one hour and represent more precise predictive criterion for the gravity of sleep-related disorders. Nevertheless the simple snoring is generally considered as an annoying disturbance, it could be early and alarming symptom of obstructive sleep apnea, requiring full medical attention. Habitual snoring is not pathophysiologically associated with flow limitations, desaturations or arousals during sleep. The difference between typical clinical presentation of moderate to severe URRS and OSA in adult patients slightly differs and could be validated by ENT-specialist on the basis of clinical examination and PSG sleep characteristics as summarized in Table 1.

Table 1. Differences in clinical presentation and sleep characteristics between URRS and OSA.

\begin{tabular}{|c|c|c|}
\hline Clinical presentation & URRS & OSA \\
\hline age & younger & $40-60$ years old \\
\hline female : male ratio & $1: 2$ & $1: 8$ \\
\hline body weight & non-obese & obese \\
\hline sleepiness & fatigue & excessive day-time sleepiness \\
\hline blood pressure & hypotension (orthostatic) & hypertension \\
\hline Seep characteristics & URRS & OSA \\
\hline onset & $\begin{array}{c}\text { insomnia } \\
\text { (sleep-onset \& sleep-maintenance) } \\
\text { parasomnias } \\
\text { (sleep walking, sleep terror) }\end{array}$ & short sleep onset \\
\hline desaturation & not significant & significant \\
\hline sleep fragmentation & $\mathrm{AHI}<5$ & $\mathrm{AHI} \geq 15$ \\
\hline RERA & $\geq 10$ & $5-10$ \\
\hline
\end{tabular}

Obstructive sleep apnea is defined as a desaturation rate bigger than $4 \%$ from the baseline in awaken condition and minimum $50 \%$ decrease on airflow or complete stop of breathing for at least 10 seconds during sleep. The exact frequency of OSA among pregnant woman is not statistically proven by metaanalysis, but it is approximately estimated that about $6 \%$ of reproductive female population could be affected ${ }^{4}$. The main reason for this inaccuracy is that the clinical assessment is based predominantly on the questionnaire survey and usually the results are not confirmed by PSG.

\section{„Hormonal storm" and pathophysiological changes}

Normal pregnancy is usually related to the series of biochemical and hormonal changes during the first and second trimester of pregnancy, while the mechanical changes (progressive weight gain, upward displacement of the diaphragm) are associated with the growing fetus inside the maternal organism, could affect significantly the sleeping patterns during the third trimester. Estrogen and progesterone levels are noticeably elevated during pregnancy and could provoke physiological changes with pathological outcome. Estrogen induces hyperemia and edema of the nasopha- ryngeal mucosa ${ }^{5}$, which result in increased upper respiratory tract resistance. During pregnancy the nasal patency could be obstructed mainly by the physiological actions of different hormones - placental trophoblastic hormone (hypertrophy of the nasal mucosa) ${ }^{6}$, progesterone (local vasodilatation and increased blood flow) and estrogen (increased histamine receptors on the nasal epithelial cells and endothelial cells with subsequent stimulation of the neo-microvascularisation) ${ }^{7}$. Increased resistance of upper respiratory tract in a combination with physiological hypervolemia in pregnant women could amplify significantly the risk of SDB during pregnancy, which is more pronounced in the third trimester ${ }^{8}$. Estrogen disrupts significantly the sleep architecture by inhibiting REM sleep 9 . Progesterone is produced mainly by the placental tissue at the moment of implantation and overrides the effect of other hormones during the first trimester. It is considered that progesterone exerts strong sedative effect resulting in increased total sleep time and decreased sleep latency ${ }^{10}$. On the other hand, progesterone has a stimulating effect over the sensitivity of respiratory center towards $\mathrm{CO}_{2}$ and thus stimulates respiration ${ }^{11}$. Physiological levels of cortisol start progressively to increase from $25^{\text {th }}$ to $28^{\text {th }}$ gestational week and rapidly normalize after delivery. The pathophysiological effect of the cor- 
tisol is probably related to reduction of REM sleep duration throughout the prenancy ${ }^{12}$. Functional residual capacity (FRC) of the lungs is decreased by upward displacement of the diaphragm during the third trimester, which is supplementary to the physiological reduction of FRC during sleep ${ }^{13}$. The described pathophysiological changes are associated with diminished maternal oxygenation ${ }^{14}$ as well as increased collapsibility of the pharyn $x^{15}$.

\section{Clinical considerations and complications}

Pregnancy-related SDB could be demonstrated in the wide range of symptoms during sleep in the clinical spectrum from habitual snoring to obesity-related hypoventilation syndrome, which is arguably considered as the most severe form of the disease in pregnant women ${ }^{16}$. Snoring is very common clinical finding among pregnant women and the prevalence is estimated about 14\%, which is significantly higher in comparison with the incidence in non-pregnant female population (approximately $4 \%)^{17}$. Furthermore snoring is a nonspecific clinical observation and usually starts at the end of the second trimester. In the same time snoring is the most frequent complaint of OSA during pregnancy, especially in obese women. Gestational rhinitis (GR) is a pathological condition which differs significantly from the more familiar and popular entity rhinitis during pregnancy (RPr). RPr encompass all types of rhinitis, which could possibly appear before, during and after pregnancy, regardless of the etiology (inflammatory, allergic, non-allergic, drug induced, vasomotor and etc.). GR typically emerges during pregnancy in the second or third trimester, lasts at least 6 weeks or longer and disappears about 2 weeks postpartum ${ }^{18}$. GR is not associated with allergic or inflammatory conditions and usually is attributed to the hormonal changes. On the basis of clinical signs and questionnaire survey the prevalence of GR is estimated about $9 \%$ at the time of delivery ${ }^{19}$. Obstructed nasal breathing, rhinorrhea and impaired quality of life are not the only outcomes of GR. Worsening of the sleep quality, snoring and gravity of apnea of the childbearing woman with OSA could be attributed to the GR, especially in those clinical cases associated with overweight during pregnancy ${ }^{20}$. Furthermore, oral breathing as a result form nasal obstruction leads to decrease in nitric oxide (NO) inhalation in the lungs with further negative effect on the maternal blood pressure, preeclampsia, retarded intrauterine fetus growth, lower Apgar score of the newborn and etc. ${ }^{21}$ Recently an attempt has been made to establish the exact prevalence of obstructive sleep apnea among pregnant women overcoming the imperfections of the traditional screening tools and has been validated that the occurrence is about $4.9 \% \%^{22}$. OSA is characterized by repeated cessation of the respiratory airflow, accompanied by oxygen desaturation and arousals. Significant reduction of nocturnal saturation of the peripheral blood during the third trimester of pregnancy has been reported in comparison with the results of the postpartum PSG studies of the same subjects ${ }^{23}$. Recurring episodes of respiratory obstruction during sleep could lead to maternal hypoxemia. Hypoxemia during sleep has been established both in normotensive and hypetrtensive pregnancies around the third trimester ${ }^{24}$. It has been speculated that SDB-related intermittent hypoxia could in turn provoke oxidative stress and endothelial activation ${ }^{25}$, which are major factors in development of pregnancy-induced hypertension ${ }^{26}$. Maternal complications such as hypertension and preeclampsia are frequently reported to be related to OSA during pregnancy and generally have been characterized by the absence of nocturnal dipping in systolic blood pressure ${ }^{27,28}$. Mild sleep-induced inspiratory flow limitations were detected during the polysomnography in preeclamptic women and subsequently disappear after continuous positive airway pressure therapy. This process is accompanied by normalization of the blood pressure, demonstrating a possible causative connection between OSA and hypertension ${ }^{29}$. The described minor inspiratory flow limitations couldn't be classified as apnea or hypopnea and typically are not associated with arousals. As a negative outcome in pregnant women with OSA has been also described gestational diabetes ${ }^{30}$. Clinical course of maternal OSA is frequently related to hypertension and peripheral vasoconstriction, which could possibly play a role in reduction of placental flow and subsequent harmful for the fetus. It has been proven by clinical survey with questionnaires and subsequently validated through PSG that even the mild OSA cases could contribute for the fetus growth retardation and increased risk of stillbirth in the late pregnancy $^{31}$. On the other hand, increased number of pathologic conditions in the postnatal period is attributed to the OSA during pregnancy - low birth weight, small for gestation age infant, preterm birth and low Apgar scores ${ }^{32}$. 


\section{Diagnostic approach}

Questionnaires are very effective tool for screening purposes and early detection of the subtle precursors indicative for OSA during pregnancy such as: sleepiness, fatigue, snoring, witnessed apneic episodes and etc. Daytime sleepiness associated with pregnancy is considered to be normal clinical observation and taking into account the natural women hesitation to complain about snoring, gasping and other "uncomfortable" topics, frequently leads to significant delay of OSA diagnosis. Epworth Sleepiness Scale (ESS) has been routinely used for assessment of the degree of daytime sleepiness and probability to fall asleep in different situations. The maximal test score is 26 and the results $\geq 10$ are with increased risk for OSA. It has to be mentioned that sleepiness is not very specific for OSA during pregnancy because of the regular daytime nap or subjective interpretation of the symptom rather as a fatigue, "unrefreshed" condition or tiredness than sleepiness. Additionally, sleepiness could not be typically observed in pregnant and preeclamtptic women ${ }^{33}$ which requires supplementary screening tools for objective and prŭcised evaluation such as multiple sleep latency test (MSLT). MSLT was originally proposed as a diagnostic tool for narcolepsy which evaluates the degree of sleepiness and how fast the patient falls asleep. MSLT is a full day test, which consists of 5 scheduled naps throughout the day separated by 2 hours intervals. The combination of ESS and MSLT could be an effective tool for early detection of OSA during pregnancy. The quality of sleep and sleep disordered breathing are effectively evaluated by another symptom based screening questionnaire, called Berlin questionnaire $(\mathrm{BQ})^{34}$. BQ consists of 10 questions subdivided in 3 groups - snoring, sleepiness and body weight (plus chronic hypertension) and the effectiveness of clinical application of BQ for early OSA diagnosis in non-pregnant population has been estimated at up to $86 \%$ sensitivity and $95 \%$ specificity ${ }^{35}$. Controversially the high-score results from BQ in pregnant women are not reliable predictors for OSA, especially in those risk groups related to obesity ${ }^{36}$.

ENT consultation is major diagnostic approach for establishing the presence and gravity of increased upper respiratory tract resistance during pregnancy. Anterior rhinoscopy is valuable and informative method which determines the level of obstruction (nasal septum deviation, hypertrophy of the inferior turbinate, etc). The most important anatomical sites, which could generate significant obstruction in the upper respiratory tract, lay at the level of the nasal valve and glottis area. Nasal segment of the URT is capable of creating almost 5-6 times higher resistance than the pharyngeal segment ${ }^{37}$. Nasal endoscopy is effective method for discovering of co-morbid pathology (sinusitis, nasal polyposis) which could contribute to increase URT resistance. Mbller's maneuver (MM) is easy to perform yet informative tool for fast evaluation of collapsibility of the retropalatal and retroglossal areas in awaken condition. Regardless the inconsistencies of result interpretation and relatively low predictive value for development of OSA, MM is still applicable in daily routine practice of otorhinolaryngologists for determining the level of obstruction. Originally developed for assessment of anatomical difficulties created by the palatal tonsil and the tongue during endotracheal intubation, the Mallampati score is easy to calculate and to determine the degree of pharyngeal edema accompanying different periods of pregnancy (mainly 12 and 38 gestation week) as a prerequisite of increased URT resistance ${ }^{38}$.

Polysomnography is the golden standard for diagnosis of obstructive sleep apnea during pregnancy. Generally PSG study of pregnant women could be conducted in the same manner as in non-pregnant women, without any concern about possible contraindications ${ }^{39}$. It should be taken into consideration that generally pregnant women prefer to lay in bed in lateral position, which could affect the prŭcised registration of AHI score. PSG study is recommended not only in cases with severe complications (gestational hypertension, gestational diabetes preeclampsia, intrauterine growth retardation of the fetus, etc.) and clinical cases with obesity-complicated pregnancies ${ }^{40}$. The evaluation of specific diagnostic criteria such as: inspiratory flow limitations (IFL) and RDI required overnight full PSG study using nasal cannula with pressure transducer and termistor, which is not possible in conventional polygraphy used predominantly for screening purposes ${ }^{40}$. Determining IFL is essential step in precise diagnosis of abnormal respiratory events in preeclamptic women, which are generally not associated with apneic episodes and are detected during the abnormal rise of blood pressure ${ }^{41}$. 


\section{Treatment strategies}

Symptomatic conservative treatment is defined by the application of different medication which doesn't have curative effect, but rather temporally relive of the clinical complaints. The general prophylactic measures ${ }^{42}$ (elevated $>30^{\circ}$ position of the head during sleep, sleeping on a lateral position, physical exercises, weight control, improving sleep hygiene, avoiding alcohol and sedatives, etc. $)^{43}$ and topical application of saline solutions (especially hypertonic) could be beneficial for the save and temporally relieve of GR symptoms ${ }^{18}$. Pregnant women with GR are frequently obsessed with the usage of topical decongestants for a prolonged period of time. The inadequate usage (longer than 5 days, application during the $1^{\text {st }}$ trimester or close to delivery term as well as inappropriate higher dosage) of $\alpha$-mimetics (phenylephrine, naphazoline, oxymetazoline and xylometazoline) leads to tachyphylaxis and negative effect on the nasal mucosa (drug-associated rhinitis), increased contractility of the uterus (preterm birth) plus possible congenital defects (pyloric stenosis, renal abnormalities) $)^{44}$. Systemic decongestants (pseudoephedrine, phenylpropanolamine) taken especially during the $1^{\text {st }}$ trimester of pregnancy are associated with life threatening conditions such as: gastroschisis, endocardial wall closure defects and external ear malformations ${ }^{45}$. Considering the negligible clinical improvement of the natural course of GR and possible teratogenic effects of wide range of drugs (local and systemic corticosteroids, antihistamines, anti-leukotrienes inhibitors) it is not recommended to be used as a treatment strategy in co-morbid allergic rhinitis during pregnancy. In those cases it is more appropriate to use sodium cromoglycate or topical ipratropium bromide to cope with the severe rhinorrhea of moderate to severe allergic rhinitis during pregnancy ${ }^{18}$.

Oral appliances are effective in reduction of upper respiratory tract resistance by pulling forwards genioglossus muscle, expanding pharyngeal anteroposterior dimensions. Dental appliances usually find application for treatment of habitual snoring and mild to moderate OSA. As a major drawback of mandibular advancement devices could be pointed out a relatively long period of time necessary for fabrication and adjustment (titrating) according to individual needs of the patient ${ }^{46}$.

Positive airway pressure (PAP) is a gold standard for conservative treatment of OSA during pregnancy. Continuous positive airway pressure
(CPAP) therapy is safe, generally well-tolerated and effective treatment with significant outcomes both for the mother (overcome apneic episodes, improves flow limitations, increase nocturnal oxygenation, reduce arterial pressure, etc.) and the fetus (improved fetal movements, change in movement patterns, reduced fetal hiccups) especially in preeclamptic patients ${ }^{47}$. The application of CPAP therapy during pregnancy is recommended for mild to moderate (AHI, 5-30/hour) and severe (AHI, > 30/hour) OSA cases associated with desaturation level $\leq 90 \%{ }^{48}$. CPAP therapy during pregnancy is consistent with very good compliance level ${ }^{39}$, even in cases when OSA is combined with preeclampsia as co-morbidity ${ }^{49}$. The usage of nasal CPAP during pregnancy is not associated with any adverse effects $^{50}$ and usually is terminated 2 weeks after delivery. The main target of CPAP therapy is to achieve favorable improvement of the saturation level $(>90 \%)$ and to acquire RDI level $<5$ per hour during sleep ${ }^{48}$. Pregnant women diagnosed before or in the beginning of the pregnancy with SDB usually required recalibration of the CPAP equipment around the 6 month $^{49}$. In severe cases associated with obesity-related OSA pregnancies or multiple gestations (twin pregnancies) is more favorable to use bi-level positive airway pressure (BiPAP) instead of CPAP ventilation. In order to improve the effectiveness of PAP treatment it is recommended to combine the artificial ventilation with supplementary oxygen therapy (OXT). OXT is not recommended as a primary treatment of OSA during pregnancy because of the potential risk of prolonged episodes of apnea, raised level of carbon dioxide in the circulating peripheral blood (hypercapnia) and increased ventricular irritability ${ }^{51}$.

Surgery is limited only for the most severe cases of OSA uninfluenced by the conservative treatment, patients with low compliance rate toward CPAP therapy or those clinical cases posing high-grade risk of serious complications for the pregnant woman and her baby. In cases with severe OSA secondary to GR and refractory to conservative treatment could be recommended a volume reduction of the inferior turbinate ${ }^{18}$. Considering the increased surgical risk and inconsistent long-term results performing a conventional uvulopalatopharyngoplasty (UVPP) $)^{52}$ is not recommended for treatment of OSA during pregnancy ${ }^{53}$. There is just one case in the literature reporting benefits from tracheostomy in a pregnant woman with obstructive sleep apnea ${ }^{54}$. 


\section{References:}

1. Милков М, Недев, Пл., Бенчев, Р., Вичева, Д., Тончев, Цв. Първи национален симпозиум по обструктивна сънна апнея и хъркане. Междунар бюл оториноларингол (Варна) 2014; 10: 49-51.

2. Thorpy MJ. Classification of sleep disorders. Neurotherapeutics : the journal of the American Society for Experimental NeuroTherapeutics 2012; 9: 687-701.

3. Матев Л, Милков, М., Тончев, Ц., Помакова, А., Недев, Н., Илиев, Г., Дикова, Ц., Маджова, Х. Нощна манометрия на горните дихателни пътища при хъркане и обструктивна сънна апнея. Междунар бюл оториноларингол (Варна) 2014; 2: 12-15.

4. Young T, Palta M, Dempsey J, Skatrud J, Weber S, Badr S. The occurrence of sleep-disordered breathing among middle-aged adults. The New England journal of medicine 1993; 328: 1230-1235.

5. Elkus R, Popovich J, Jr. Respiratory physiology in pregnancy. Clinics in chest medicine 1992; 13: 555-565.

6. Namazy JA, Schatz M. Diagnosing rhinitis during pregnancy. Current allergy and asthma reports 2014; $14: 458$.

7. Hamano N, Terada N, Maesako Ket al. Expression of histamine receptors in nasal epithelial cells and endothelial cells the effects of sex hormones. International archives of allergy and immunology 1998; 115: 220-227.

8. Izci B, Vennelle M, Liston WA, Dundas KC, Calder AA, Douglas NJ. Sleep-disordered breathing and upper airway size in pregnancy and post-partum. The European respiratory journal 2006; 27: 321-327.

9. Fang J, Fishbein W. Sex differences in paradoxical sleep: influences of estrus cycle and ovariectomy. Brain research 1996; 734: $275-285$.

10. Brunner DP, Munch M, Biedermann K, Huch R, Huch A, Borbely AA. Changes in sleep and sleep electroencephalogram during pregnancy. Sleep 1994; 17: 576-582.

11. Contreras G, Gutierrez M, Beroiza Tet al. Ventilatory drive and respiratory muscle function in pregnancy. The American review of respiratory disease 1991; 144: 837-841.

12. Steiger A. Neurochemical regulation of sleep. Journal of psychiatric research 2007; 41: 537-552.

13. Weinberger SE, Weiss ST, Cohen WR, Weiss JW, Johnson TS. Pregnancy and the lung. The American review of respiratory disease 1980; 121 : 559-581.

14. Awe RJ, Nicotra MB, Newsom TD, Viles R. Arterial oxygenation and alveolar-arterial gradients in term pregnancy. Obstetrics and gynecology 1979; 53: 182-186.

15. White DP. Pathogenesis of obstructive and central sleep apnea. American journal of respiratory and critical care medicine 2005; 172 : $1363-$ 1370 .

16. Izci-Balserak B. Sleep-disordered breathing in pregnancy. Int J Sleep Wakefulness 2008: 98-108.

17. Loube DI, Poceta JS, Morales MC, Peacock MD, Mitler MM. Self-reported snoring in pregnancy. Association with fetal outcome. Chest 1996; 109: 885-889.

18. Orban N, Maughan E, Bleach N. Pregnancy-induced rhinitis. Rhinology 2013; 51: 111-119.

19. Shushan S, Sadan O, Lurie S, Evron S, Golan A, Roth Y. Pregnancy-associated rhinitis. American journal of perinatology 2006; 23: 431433.

20. Namazy JA, Schatz M. Asthma and rhinitis during pregnancy. The Mount Sinai journal of medicine, New York 2011; 78 : 661-670.

21. Franklin KA, Holmgren PA, Jonsson F, Poromaa N, Stenlund H, Svanborg E. Snoring, pregnancy-induced hypertension, and growth retardation of the fetus. Chest 2000; 117: 137-141.

22. Antony KM, Agrawal A, Arndt MEet al. Obstructive sleep apnea in pregnancy: reliability of prevalence and prediction estimates. Journal of perinatology : official journal of the California Perinatal Association 2014; 34: 587-593.

23. Hertz G, Fast A, Feinsilver SH, Albertario CL, Schulman H, Fein AM. Sleep in normal late pregnancy. Sleep 1992; 15 : $246-251$.

24. Bourne T, Ogilvy AJ, Vickers R, Williamson K. Nocturnal hypoxaemia in late pregnancy. British journal of anaesthesia 1995 ; 75 : 678-682.

25. Yinon D, Lowenstein L, Suraya Set al. Pre-eclampsia is associated with sleep-disordered breathing and endothelial dysfunction. The European respiratory journal 2006; 27: 328-333.

26. Dekker GA, Sibai BM. Etiology and pathogenesis of preeclampsia: current concepts. American journal of obstetrics and gynecology 1998; 179: 1359-1375.

27. Loredo JS, Ancoli-Israel S, Dimsdale JE. Sleep quality and blood pressure dipping in obstructive sleep apnea. American journal of hypertension 2001; 14: 887-892.

28. Beilin LJ, Deacon J, Michael CAet al. Diurnal rhythms of blood pressure, plasma renin activity, angiotensin II and catecholamines in normotensive and hypertensive pregnancies. Clinical and experimental hypertension Part B, Hypertension in pregnancy 1983; 2: $271-293$.

29. Edwards N, Blyton DM, Kirjavainen T, Kesby GJ, Sullivan CE. Nasal continuous positive airway pressure reduces sleep-induced blood pressure increments in preeclampsia. American journal of respiratory and critical care medicine 2000; 162: $252-257$.

30. Qiu C, Enquobahrie D, Frederick IO, Abetew D, Williams MA. Glucose intolerance and gestational diabetes risk in relation to sleep duration and snoring during pregnancy: a pilot study. BMC women's health 2010; 10: 17.

31. Fung AM, Wilson DL, Lappas Met al. Effects of maternal obstructive sleep apnoea on fetal growth: a prospective cohort study. PloS one 2013; 8:e68057.

32. Chen YH, Kang JH, Lin CC, Wang IT, Keller JJ, Lin HC. Obstructive sleep apnea and the risk of adverse pregnancy outcomes. American journal of obstetrics and gynecology 2012; 206: 136 e131-135.

33. Izci B, Martin SE, Dundas KC, Liston WA, Calder AA, Douglas NJ. Sleep complaints: snoring and daytime sleepiness in pregnant and preeclamptic women. Sleep medicine 2005; 6: 163-169.

34. Netzer NC, Stoohs RA, Netzer CM, Clark K, Strohl KP. Using the Berlin Questionnaire to identify patients at risk for the sleep apnea syndrome. Annals of internal medicine 1999; 131: 485-491.

35. Abrishami A, Khajehdehi A, Chung F. A systematic review of screening questionnaires for obstructive sleep apnea. Canadian journal of anaesthesia = Journal canadien d'anesthesie 2010; 57: 423-438.

36. Facco FL, Ouyang DW, Zee PC, Grobman WA. Development of a pregnancy-specific screening tool for sleep apnea. Journal of clinical sleep medicine : JCSM : official publication of the American Academy of Sleep Medicine 2012; 8: 389-394.

37. Tvinnereim M, Cole P, Mateika S, Haight J, Hoffstein V. Postural changes in respiratory airflow pressure and resistance in nasal, hypopharyngeal, and pharyngeal airway in normal subjects. The Annals of otology, rhinology, and laryngology 1996; 105: $218-221$.

38. Pilkington S, Carli F, Dakin MJet al. Increase in Mallampati score during pregnancy. British journal of anaesthesia 1995; 74: 638-642.

39. Guilleminault C, Kreutzer M, Chang JL. Pregnancy, sleep disordered breathing and treatment with nasal continuous positive airway pressure. Sleep medicine 2004; 5: 43-51. 
40. Poyares D, Guilleminault C, Hachul Het al. Pre-eclampsia and nasal CPAP: part 2. Hypertension during pregnancy, chronic snoring, and early nasal CPAP intervention. Sleep medicine 2007; 9: 15-21.

41. Connolly G, Razak AR, Hayanga A, Russell A, McKenna P, McNicholas WT. Inspiratory flow limitation during sleep in pre-eclampsia: comparison with normal pregnant and nonpregnant women. The European respiratory journal 2001; 18: 672-676.

42. Петрова Г, Милков, М., Костадинова, Т., Докова, А. Интегрирани грижи - теоретични постановки и възможности за прилагането им при лечение на сънната апнея. Междунар бюл оториноларингол (Варна) 2015; 2: 11-20.

43. Ellegard EK. Special considerations in the treatment of pregnancy rhinitis. Women's health 2005; 1: 105-114.

44. Incaudo GA, Takach P. The diagnosis and treatment of allergic rhinitis during pregnancy and lactation. Immunology and allergy clinics of North America 2006; 26: 137-154.

45. Yau WP, Mitchell AA, Lin KJ, Werler MM, Hernandez-Diaz S. Use of decongestants during pregnancy and the risk of birth defects. American journal of epidemiology 2013; 178: 198-208

46. Santiago JR, Nolledo MS, Kinzler W, Santiago TV. Sleep and sleep disorders in pregnancy. Annals of internal medicine 2001; 134:396-408.

47. Blyton DM, Skilton MR, Edwards N, Hennessy A, Celermajer DS, Sullivan CE. Treatment of sleep disordered breathing reverses low fetal activity levels in preeclampsia. Sleep 2013; 36: 15-21.

48. Pien GW, Schwab RJ. Sleep disorders during pregnancy. Sleep 2004; 27: 1405-1417.

49. Guilleminault C, Palombini L, Poyares D, Takaoka S, Huynh NT, El-Sayed Y. Pre-eclampsia and nasal CPAP: part 1. Early intervention with nasal CPAP in pregnant women with risk-factors for pre-eclampsia: preliminary findings. Sleep medicine 2007; 9: 9-14.

50. Roush SF, Bell L. Obstructive sleep apnea in pregnancy. The Journal of the American Board of Family Practice / American Board of Family Practice 2004; 17: 292-294.

51. Fletcher EC, Munafo DA. Role of nocturnal oxygen therapy in obstructive sleep apnea. When should it be used? Chest 1990; 98: 14971504.

52. Недев П, Бояджиев, Г., Милков, М. Видове интервенции при лечение на хъркане и обструктивна сънна апнея. Междунар бюл оториноларингол (Варна) 2008; 2: 47-51.

53. Venkata C, Venkateshiah SB. Sleep-disordered breathing during pregnancy. Journal of the American Board of Family Medicine : JABFM 2009; 22: 158-168.

54. Hastie SJ, Prowse K, Perks WH, Atkins J, Blunt VA. Obstructive sleep apnoea during pregnancy requiring tracheostomy. The Australian \& New Zealand journal of obstetrics \& gynaecology 1989; 29: 365-367. 